\title{
Gastropancreatic fistula secondary to a pancreatic intraductal papillary mucinous neoplasia - endoscopic ultrasound and upper gastrointestinal endoscopy findings
}

\author{
Eduardo Aimore BONIN ${ }^{1}$, Raquel Canzi Almada de SOUZA ${ }^{1}$, Renata Pereira MUELLER ${ }^{1}$, \\ Sergio Ossamu IOSHII',2 and José Celso ARDENGH ${ }^{3,4}$
}

Pancreatic intraductal papillary mucinous neoplasia (IPMN) is an epithelial neoplasia, characterized by papillary proliferation and dilation of the main pancreatic duct, with consequent cyst formation $^{(1)}$. Its identification is usually made by magnetic resonance cholangiopancreatography (MRCP), which can be confirmed by endoscopic ultrasound (EUS) imaging and corroborated by fine-needle (FNA) and histopathological analysis demonstrating the presence of mucin-producing cells ${ }^{(2)}$. IPMN can present a fistulizing variant in up to $6 \%$ of cases $^{(3)}$, usually at the duodenum $(65 \% \text { of cases })^{(4)}$. A fistulizing IPMN can vary in behavior as being invasive (penetrating) due to advanced neoplasia or by compression and ischemia of the digestive tube wall (mechanical), the latter usually not associated with malignancy, and responsible for up to $2 / 3$ of the cases ${ }^{(3)}$. The authors present a case of spontaneous gastropancreatic fistula secondary to mixed type IPMN confirmed by upper gastrointestinal endoscopy and EUS.

\section{CASE REPORT}

A 68 years-old female patient came to the gastroenterology clinic in May 2018 with a complaint of postprandial fullness and abdominal discomfort for 2 years. She had type 2 diabetes mellitus for 1 year, hypothyroidism, COPD due to smoking (25 packs/year), dyslipidemia, appendectomy, and incisional herniorrhaphy. Among the routine diagnostic tests performed, there was an undetermined solid-cystic lesion in pancreatic body measuring about $3 \mathrm{~cm}$ revealed in an abdominal ultrasound. She underwent MRCP, EUS and upper endoscopy with biopsies which confirmed the hypothesis of mixed-type IPMN with gastropancreatic fistula (E-VIDEO*, FIGURE 1, FIGURE 2, FIGURE 3, FIGURE 4). A total pancreatectomy was originally planned, however, a distal pancreatectomy and partial gastrectomy with splenectomy was ultimately performed due to adhesions in the pancreatic head. The proximal ductal margin frozen section came negative for dysplasia. The final

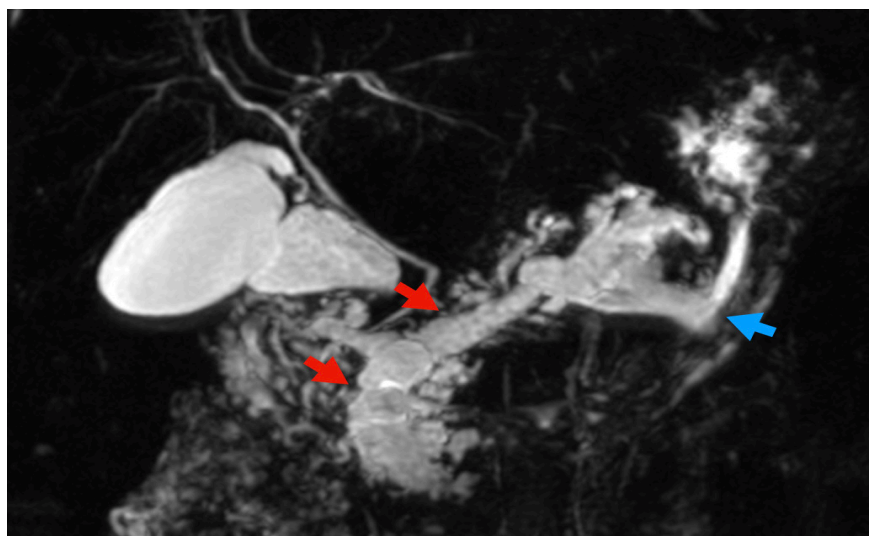

FIGURE 1. Magnetic resonance cholangiopancreatography showing marked pancreatic ductal dilatation (red arrows), parenchymal atrophy and signs of a gastropancreatic fistula (blue arrow).

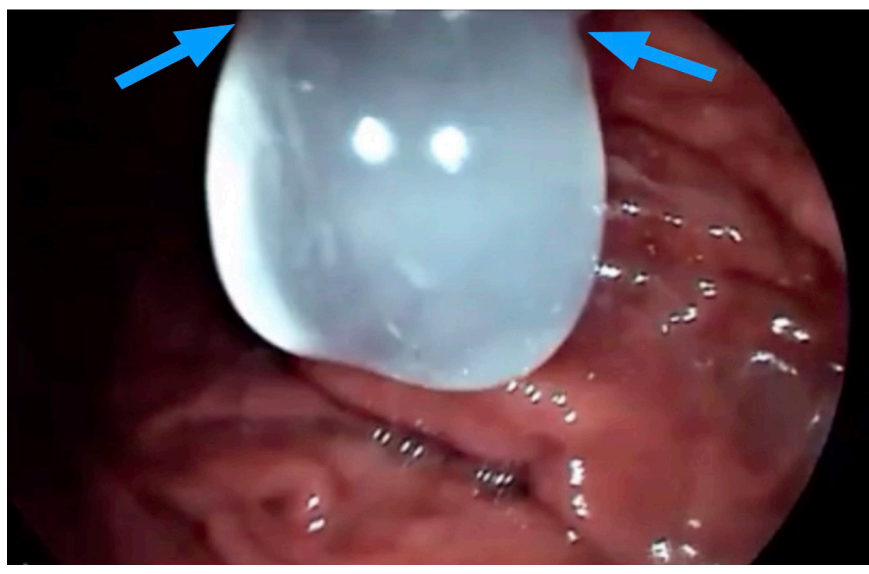

FIGURE 2. Upper gastrointestinal endoscopy imaging revealing a mucous plug drop coming from a gastropancreatic fistula orifice (blue arrows).

Declared conflict of interest of all authors: none

Disclosure of funding: no funding received

${ }^{1}$ Universidade Federal do Paraná, Complexo Hospital de Clínicas, Curitiba, PR, Brasil. ${ }^{2}$ Pontifícia Universidade Católica do Paraná (PPGTS), Curitiba, PR, Brasil. ${ }^{3}$ Hospital das Clínicas da Faculdade de Medicina de Ribeirão Preto da Universidade de São Paulo (HCFMRP-USP), Ribeirão Preto, SP, Brasil. ${ }^{4}$ Hospital 9 de Julho, Setor de Endoscopia, São Paulo, SP, Brasil.

Corresponding author: Eduardo Aimore Bonin. E-mail: eabonin@gmail.com

*E-VIDEO: https://youtu.be/K4YRop2vCok 


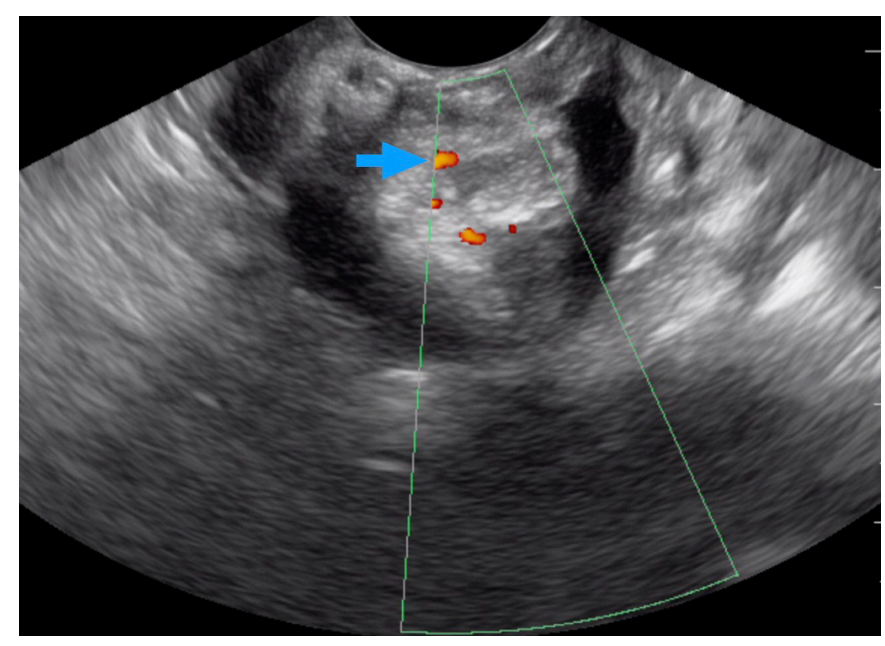

FIGURE 3. Endoscopic ultrasound imaging revealing a dilated main pancreatic duct and a doppler-positive vegetation (blue arrow).

histopathological diagnosis was high grade dysplasia and no invasive cancer. The patient was discharged 11 days after surgery. Six months later she was admitted to hospital for diarrhea and malnutrition which responded to nutritional therapy and pancreatic enzyme upscaling. She died a month later due to sepsis from unknown origin.

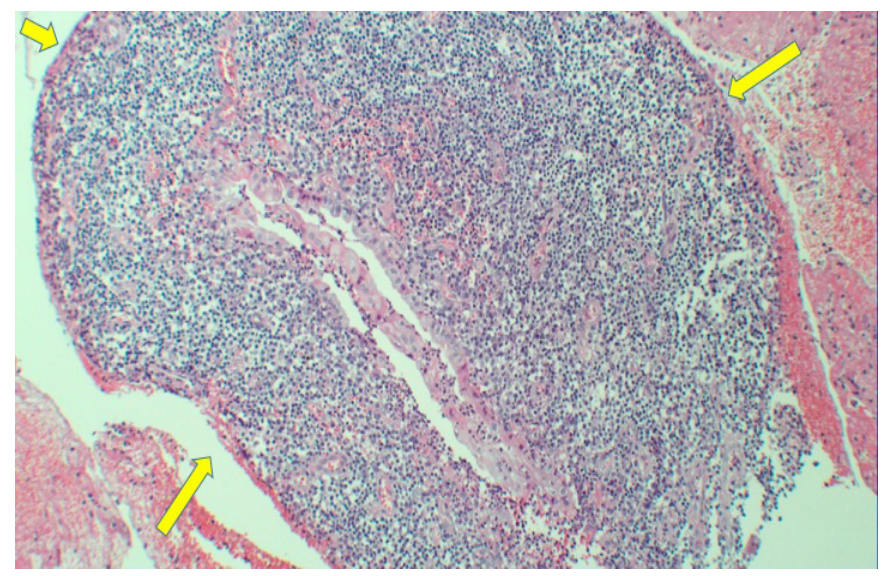

FIGURE 4. Upper endoscopy biopsy histopathological examination confirmed the presence of intestinal papilliform epithelium with high-grade dysplasia, corroborating the diagnosis of mixed-type intraductal papillary mucinous neoplasia. Hematoxylin-eosin 40x.

\section{Orcid}

Eduardo Aimore Bonin: 0000-0001-8463-2993.

Raquel Canzi Almada de Souza: 0000-0002-4860-3340.

Renata Pereira Mueller: 0000-0002-0969-6230.

Sergio Ossamu Ioshii: 0000-0002-7871-4463.

José Celso Ardengh: 0000-0002-5932-2499.

Bonin EA, Souza RCA, Mueller RP, Ioshii SO, Ardengh JC. Fístula gastropancreática secundária à neoplasia intraductal mucinosa papilar pancreática - achados de endoscopia digestiva alta e ultrassom endoscópico. Arq Gastroenterol. 2021;58(2):262-3.

\section{REFERENCES}

1. Tanaka M, Chari S, Adsay V, Fernandez-del Castillo C, Falconi M, Shimizu M. International consensus guidelines for management of intraductal papillary mucinous neoplasms and mucinous cystic neoplasms of the pancreas. Pancreatology. 2006;6:17-32.

2. Machado NO, Al Qadhi H, Al Wahibi K. Intraductal papillary mucinous neoplasm of pancreas. N Am J Med Sci. 2015;7:160-75.
3. Kobayashi G, Fujita N, Noda Y, Ito K, Horaguchi J, Obana T. Intraductal papillary mucinous neoplasms of the pancreas showing fistula formation into other organs. J Gastroenterol. 2010;45:1080-9.

4. Ravaud S, Laurent V, Jausset F, Cannard L, Mandry D, Oliver A. CT and MR imaging features of fistulas from intraductal papillary mucinous neoplasm of the pancreas to adjacent organs: a retrospective study of 423 patients. Eur J Radiol. 2015;84:2080-8. 